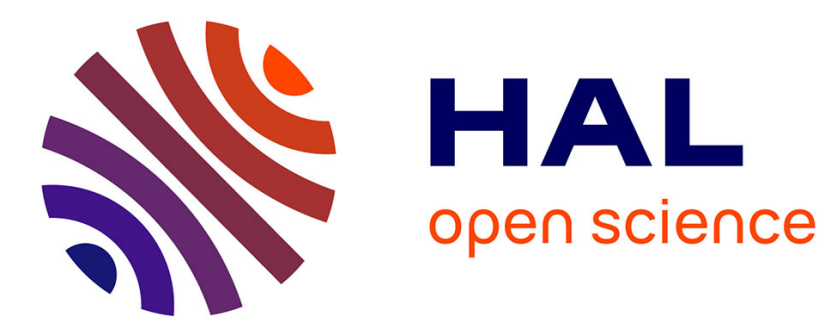

\title{
On calculating sterility in thermal preservation methods : application of the Weibull frequency distribution model
}

Pierre Mafart, Olivier Couvert, Stéphane Gaillard, Ivan Leguérinel

\section{- To cite this version:}

Pierre Mafart, Olivier Couvert, Stéphane Gaillard, Ivan Leguérinel. On calculating sterility in thermal preservation methods: application of the Weibull frequency distribution model. International Journal of Food Microbiology, 2002, pp.107- 113. hal-00654614

\section{HAL Id: hal-00654614 \\ https://hal.univ-brest.fr/hal-00654614}

Submitted on 22 Dec 2011

HAL is a multi-disciplinary open access archive for the deposit and dissemination of scientific research documents, whether they are published or not. The documents may come from teaching and research institutions in France or abroad, or from public or private research centers.
L'archive ouverte pluridisciplinaire HAL, est destinée au dépôt et à la diffusion de documents scientifiques de niveau recherche, publiés ou non, émanant des établissements d'enseignement et de recherche français ou étrangers, des laboratoires publics ou privés. 


\section{On calculating sterility in thermal preservation methods :} application of the Weibull frequency distribution model.

ABSTRACT A simple and parsimonious model originated from the Weibull frequency distribution was proposed to describe non linear survival curves of spores. This model 10 was suitable for downward concavity curves (Bacillus cereus and Bacillus pumilus) as 11 well as for upward concavity curves (Clostridium botulinum). It was shown that 12 traditional F-values calculated from this new model were no more additive, to such an 13 extend that a heat treatment should be better characterized by the obtained decade 14 reduction of spores. A modified Bigelow method was then proposed to assess this decade 15 reduction or to optimize the heat treatment for a target reduction ratio.

16 KEYWORDS: spores, heat treatment, F-value, Weibull

\section{INTRODUCTION}

18 The conventional way of calculating the efficiency of heat treatments in food protection is

19 based on the assumption that survival curves of microbial cells and bacterial spores are 20 governed by a first order kinetic. Consequently, a linear relationship between the decimal 21 logarithm of the number of surviving microorganisms and the treatment time at a given 22 temperature is used to estimate the D-value (time of decimal reduction). However, in many 23 cases, the survival curve of heated microorganisms is not linear and present a downward 24 concavity (presence of a shoulder) or an upward concavity (presence of a tail). A number of 25 models describing non linear survival curves were proposed. Some of them are mechanistic or 
26 pseudo-mechanistic (Brynjolfsson, 1978; Casolari, 1988; Kilsby et al., 2000; Rodriguez et

27 al., 1988; Sapru et al., 1992 and 1993; Shull et al., 1963; Xiong et al., 1999) while others are 28 purely empirical (Badhuri et al., 1991; Baranyi, 1996; Buchanan et al., 1997; Chiruta et al.,

29 1997; Cole et al., 1993; Daughtry et al., 1997; Geeraerd et al., 1999; Linton et al., 1995;

30 Whiting, 1993). These models generally present a satisfying goodness of fit, but they lack of

31 robustness and are adapted to some particular situations only. Moreover, parameters of

32 mechanistic models can be difficult to estimate, while parameters of empirical models have

33 generally no easily interpretable physical or biological significance. For both kinds of

34 equations, the number of parameters exceeds three or four, to such an extend that the

35 complexity of models prevents them from being applied to heat treatment calculations.

36 While the conventional first order model implicitly assumed that microbial populations are

37 homogeneous from the point of view of their heat resistance, some researchers (Fernandez et

38 al., 1999; Peleg, 1999; Peleg and Cole, 1998 and 2000) assumed that , at a given temperature,

39 the time of heat exposure which caused the death of a microbial cell or a bacterial spore is

40 variable from one individual to the other, and that the dispersion of individual heat resistance

41 was governed by a Weibull distribution, the cumulative form of which yields:

$42 \quad N=N_{0} e^{-k t^{p}}$

43 Where $\mathrm{N}$ represents the number of surviving cells after a duration of heat treatment $\mathrm{t}$, while

$44 \mathrm{~N}_{0}$ is the initial size of the alive population. For a given temperature, parameter distribution 45 are $\mathrm{k}$ and $\mathrm{p}$.

46 Peleg and Cole (1998) wrote out this model in the following decimal logarithmic form:

$47 \quad \log \frac{N}{N_{0}}=-b t^{p}$ 
49 The cited authors successfully checked the model for Clostridium botulinum and Bacillus

50 stearothermophilus spores and Salmonella thyphimurium and Listeria monocytogenes cells.

51 Similarly, Fernandez et al. (1999) successfully applied the same model to the heat destruction

52 of Bacillus cereus. Such a model presents the main advantage of remaining very simple and

53 being sufficiently robust to describe both downward concave survival curves $(p>1)$ and

54 upward concave curves $(\mathrm{p}<1)$. Obviously, the model includes the traditional case where the 55 survival curve, originated from a first order, is linear $(\mathrm{p}=1)$.

56 The present paper aims to improve the parameterization of the model, to propose a new 57 method of assessing the efficiency of heat treatments and to bring the traditional F-value 58 concept up to date.

\section{Material and methods}

60 Microorganism and spore production. The strain of Bacillus cereus was isolated from dairy

61 food line process, the strain of Bacillus pumilus from eggs powder. Spores were kept in 62 distilled water at $4^{\circ} \mathrm{C}$. Cells were precultivated at $37^{\circ} \mathrm{C}$ during 24 hrs in Brain Heart Infusion 63 (Difco ). The preculture was used to inoculate nutritive agar plates (Biokar Diagnostics 64 BK021) added with $\mathrm{MnSO}_{4} 40 \mathrm{mg} \mathrm{l}^{-1}$ and $\mathrm{CaCl}_{2} 100 \mathrm{mgl}^{-1}$ on the surface area. Plates were 65 incubated at $37^{\circ} \mathrm{C}$ for 5 days. Spores were then collected by scraping the surface of the agar 66 and suspended in sterile distilled water and washed three times by centrifugation (10000xg for $6715 \mathrm{~min}$ ) (Bioblock Scientific, model Sigma 3K30). The pellet was then resuspended in $5 \mathrm{ml}$ 68 distilled water and $5 \mathrm{ml}$ ethanol. The obtained suspension was then kept at $4^{\circ} \mathrm{C}$ during 12 69 hours in order to eliminate vegetative non sporulated bacteria, and washed again three times 70 by centrifugation.

71 Lastly the final suspension (about $10^{10}$ spores $\mathrm{ml}^{-1}$ ) was at last distributed in sterile Eppendorfs 72 microtubes and kept at $4^{\circ} \mathrm{C}$.

73 Thermal treatment of spore suspension. 
74 First, $30 \mu \mathrm{l}$ of spore suspension was diluted in $3 \mathrm{ml}$ heating medium. Capillary tubes of $25 \mu 1$ 75 (vitrex) were filled with $10 \mu \mathrm{l}$ of sample and submitted to a thermal treatment in a

76 thermostated oil bath. After heating, the tubes were cooled in water/ice bath, washed in a

77 solution of soap and rinsed with sterile distilled water. Finally, ends were flamed with

78 ethanol. The capillary tubes were broken at both ends and their contents poured into a tube

79 containing $9 \mathrm{ml}$ sterile tryptone salt broth (Biokar Diagnostics) by rinsing with $1 \mathrm{ml}$ tryptone

80 salt broth contained in a needle-equipped syringe.

81 Data analysis

82 For each spore species, a single $\mathrm{p}$ value was estimated from the corresponding whole set of

83 data according to a non-linear regression by using the solver capability of the Excel software.

84 Each survival curve was then fitted according to Eqn 3 by a linear regression.

85

86 Results and discussion

87

88

1. Improvements of the model

89

90 Parameter $\mathrm{b}$ of the last equation has no immediate physical significance and has the

91 dimensions of a time power $-\mathrm{p}$, so we preferred to reparameterize the model into the

92 following form:

$93 \log \frac{N}{N_{0}}=-\left(\frac{t}{\delta}\right)^{p} \quad$ or $\log N=\log N_{0}+\left(\frac{-1}{\delta^{p}}\right) \times t^{p}$

94 Or

$95 n=\left(\frac{t}{\delta}\right)^{p}$ 
97 Where $\mathrm{n}$ represents the decimal reduction ratio. Parameter $\delta$ which has now the simple 98 dimensions of a time, can be called time of first decimal reduction: contrarily to the 99 conventional D-value which is originated from the first order kinetic and which represents the 100 time of decimal reduction, regardless of the time of heating, the significance of the $\delta$-value is 101 restricted to first decimal reduction of surviving spores or cells from $\mathrm{N}_{0}$ to $\mathrm{N}_{0} / 10$.

102 This model, if unmodified, presents two major drawbacks: first, assessment of parameters 103 requires a non linear regression. Secondly, $\mathrm{p}$ which is a shape parameter, is structurally 104 strongly correlated with $\delta$ values. That is to say, both parameters are not independent: an error 105 on $\delta$ will be balanced by an error on $\mathrm{p}$ in the same way. Such an autocorrelation causes a 106 certain instability of parameter estimates. See for example $\mathrm{p}$ values estimated by Peleg and 107 Cole (1998) for C botulinum (table 1).

108 As $\mathrm{p}$ values are expected to be dependent on temperature, we calculated correlation 109 coefficients between $\mathrm{p}$ and heating temperature (Table 2). It can be seen that, for the three sets 110 of data, correlation coefficients are poor. For B. cereus, the correlation is not significant, 111 while for $C$ botulinum and B. pumilus, correlation coefficients just reach the significance 112 threshold (at the level $\mathrm{p}=0.05$ ). Then, it seems worthwhile to fix $\mathrm{p}$ at an average value, 113 characteristic of a strain, so that $\mathrm{N}_{0}$ and $\delta$ values can be estimated from a linear regression.

114 Obviously, the fixation of $\mathrm{p}$ will have repercussions on $\delta$ values which, as expected, are 115 governed by the Bigelow relationship as a function of temperature. For the previously cited 116 set of data regarding $C$ botulinum, when $\mathrm{p}$ and $\delta$ were estimated together from a non linear 117 regression, we obtained the following results:

$119 \mathrm{z}=7.09^{\circ} \mathrm{C} ; \mathrm{r}=0.969$ 
121 When $\mathrm{p}$ was fixed to its average value $(\mathrm{p}=0.346)$ and $\delta$ estimated from a linear regression, it 122 yielded:

$124 \mathrm{z}=8.58^{\circ} \mathrm{C} ; \mathrm{r}=0.989$

125

126 Because the fixation of $\mathrm{p}$ causes a better stability of $\delta$ estimates, the clear improvement of the

127 concerned correlation coefficient was expected. Similarly, average p-values regarding $B$.

128 cereus and $B$. pumilus were determined and respective $\mathrm{z}$-values assessed. Results are 129 presented in Table 3. It is them confirmed that $\delta$-values have the same dependence 130 relationship towards temperature as conventional D-values:

$131 \delta=\delta * 10^{-\frac{T-T^{*}}{z}}(5)$

133 Where $\delta^{*}$ is the time of first decimal reduction at the reference temperature $\mathrm{T}^{*}$.

\section{Application of the model to calculations of heat treatment efficiency}

137 The traditional sterilization value (F-value) is defined as the time of a heat treatment at the 138 reference temperature (generally, $\mathrm{T}^{*}=121.1^{\circ} \mathrm{C}^{\circ}$ ), or as any equivalent heat treatment which 139 would cause the same destruction ratio. The target F-value which depends both on the 140 required level of safety and on the heat resistance of the target species of spore or bacterial 141 cell, is:

$143 \quad \mathrm{~F}=\mathrm{nD}^{*}(6)$ 
145 Where $\mathrm{n}$ is the ratio of decimal reduction (safety level) and $\mathrm{D}^{*}$, the time of decimal reduction

146 at the reference temperature (heat resistance).

147 At a constant temperature, the actual F-value is the product of the heating time and the so

148 called Biological Destruction value $\mathrm{L}$, which is a function of temperature:

$150 \quad \mathrm{~F}=\mathrm{L}(\mathrm{T}) \mathrm{t} \quad(7)$

151 With

$152 L(T)=10^{\frac{T-T^{*}}{z}}$

153 In standard calculations, the z-value is assumed to be $10^{\circ} \mathrm{C}$, which corresponds to that of $C$.

154 botulinum. Then, the traditional F-value is implicitly applied to an ideal strain of $C$.

155 botulinum, the destruction curve of which would be governed by a first order kinetic, and

156 which would be characterized by a $\mathrm{z}$-value of $10^{\circ} \mathrm{C}$. Because F-values are additive, in the case

157 of a variable temperature heat treatment, it can be written:

$158 \quad F=\int_{0}^{t} L(T) d t \quad(9)$

159 Bigelow numerically solved this equation by writing it in the following discrete form:

$160 \quad F=\sum L\left(T_{i}\right) \Delta t_{i} \quad(10)$

161 Where increments $\Delta \mathrm{t}_{\mathrm{i}}$ were equally fixed at 1 minute.

163 If it is assumed that, instead of obeying to a first order kinetic, survival curves of spores are

164 governed by the Weibull frequency distribution model, F-values are no more additive. Let F 165 be the overall sterilization value resulting from two successive heat treatments whose 166 sterilization values would be $F_{1}$ anf $F_{2}$ respectively. The first heat treatment would cause a 167 decimal destruction ratio: 
$169 n_{1}=\log \frac{N_{0}}{N_{1}}$

170 where $N_{1}$ is the number of surviving cells after the first heating. Similarly, the second

171 treatment would cause a decimal destruction ratio:

$172 n_{2}=\log \frac{N_{1}}{N_{2}}$

$173 n=\log \frac{N_{0}}{N_{2}}=\log \frac{N_{0}}{N_{1}} \frac{N_{1}}{N_{2}}=\log \frac{N_{0}}{N_{1}}+\log \frac{N_{1}}{N_{2}}=n_{1}+n_{2}$

174 where $\mathrm{N}_{2}$ is the number of surviving cells after the second heating. Lastly, the overall heat

175 treatment would yield:

176

177 According to the new model,

$178 n=\left(\frac{t}{\delta}\right)^{p}=\left(\frac{F}{\delta^{*}}\right)^{p}$

179 So that

$180 \quad\left(\frac{F}{\delta^{*}}\right)^{p}=\left(\frac{F_{1}}{\delta^{*}}\right)^{p}+\left(\frac{F_{2}}{\delta^{*}}\right)^{p}$

181 And

$182 \quad F^{p}=F_{1}^{p}+F_{2}^{p} \quad(15)$

183 The F-value being no more additive, it is clear that the destruction ratio is no more

184 proportional to this value, so that the $\mathrm{F}$ concept loses a great part of its relevance.

185 Consequently, the decimal reduction ratio becomes the only convenient indicator of the heat

186 treatment efficiency.

187 At constant temperature,

$188 n=\left[\frac{L(T) t}{\delta^{*}}\right]^{p}$ 
Then,

$190 \quad d n=p\left[\frac{L(T)}{\delta *}\right]^{p} t^{p-1} d t$

191 So

$192 n=p \int_{0}^{t}\left[\frac{L(T)}{\delta *}\right]^{p} t^{p-1} d t$

193 that, at variable temperature,

194 A procedure similar to that of Bigelow can then be applied to solve numerically this last

195 equation from the following discrete form:

$196 n=p \sum_{1}^{m}\left[\frac{L\left(T_{i}\right)}{\delta^{*}}\right]^{p} t_{i}^{p-1} \Delta t_{i}$

197 An adjusted F-value (adjusted according to the $\mathrm{p}$ and $\mathrm{z}$ values of the target microorganism)

198 can then be calculated from the following equation:

$199 F=n^{\frac{1}{p}} \delta^{*}(20)$

200 Indeed, the conventional F-value, which could be called the standard F-value remains an

201 interesting criterion, as it allows to intrinsically compare several heat treatments, regardless of

202 the target species which is to be destroyed.

203

204 Figure 1 represents registrations of a retort temperature (with an average value of $115.3^{\circ} \mathrm{C}$ )

205 and inside temperature of a canned tomato sauce. The Bigelow procedure (1920) allows to

206 calculate a conventional F-value of 7.31. Assuming a $\mathrm{D}^{*}$-value of 0.21 minutes, the decimal

207 destruction ratio which theoretically would be reached after the sterilization run would be $\mathrm{n}=$

208 34.8. Data showed in Table 3 yield for C. botulinum the following estimates:

$209 p=0.346$

$210 \quad \delta^{*}=0.00527$ 
$211 \mathrm{z}=8.58^{\circ} \mathrm{C}$

212 An actual decimal destruction ratio of 6.18 and an adjusted F-value of 1.02 can be then

213 calculated. A 12 decade reduction of $C$. botulinum being conventionally proposed, for

214 reaching this reduction ratio, the actual sterilization would have to be prolonged to obtain a

215 further decimal reduction $\Delta \mathrm{n}$ :

$216 \Delta \mathrm{n}=12-6.18=5.82$

217

218 From Eqn 17, it can be deduced that the corresponding prolongation time would be:

$219 \quad t=\frac{\Delta n^{\frac{1}{p}} \delta *}{L(T)}$

221 At an assumed heart stationary product temperature of $115.3^{\circ} \mathrm{C}$, the needed prolongation time

222 of sterilization would then be 3.85 minutes, while the adjusted F-value would become 4.09

223 (for a standard F-value which would become 8.32)

224 Indeed, applications of the Weibull frequency distribution are not likely to render traditional 225 concepts out of date: the conventional F-value concept remains highly useful. However heat 226 treatment calculations require some modifications when survival curves of spores or bacterial 227 cells are not linear. We presented an adaptation of the Bigelow method based on the Weibull 228 frequency distribution method for assessing the efficiency of sterilization. Similarly, further 229 useful investigations to adapt the analytical approach of Ball (1923) would be possible. 
REFERENCES

232 Ball, C.1923.Thermal process time for canned food.Bull.7-1,(37)Natl. Res. Council, Washington, DC.

233 Baranyi,J., Jones, A., Walker, C., Kaloti, A., Robinson, T. P. and Mackey, B. M. 1996. A combined model for

234 growth and subsequent thermal inactivation of Brochothrix thermophacta. Appl. Environ. Microbiol. 62: 1029-

2351035.

236 Bhaduri, S., Shmith, P. W., Palumbo, S. A., Turner-Jones, C. O., Smith, J.L. Marmer, B. S., Buchanan, R. L., 237 Zaika, L. L. and Williams, A. C. 1991. Thermal destruction of Listeria monocytogenes in liver sausage slurry. 238 Food Mocrobiol. 8: 75-78.

239 Bigelow W., Bohart, G., Richardson,A. and Ball, C. 1920. Heat penetration in processing canned foods. Bull.

240 16-L. Res. Lab. Natl. Canner Ass. Washington, DC.

241 Brynjolfsson, A. 1978. Mathematical models for microbial kill by radiation. In: Food preservation by irradiation.

242 Proceedings, International Atomic Energy Agency IAEA-SM-221/56, Vienna, Vol. 1, pp. 227-239.

243 Buchanan, R. L., Whiting, R. C. and Damert, W. C. 1997.When simple is good enough: a comparison of the

244 Gompertz, Baranyi and the three-phase linear models for fitting bacterial growth curves. Food Microbiol. 14:

$245313-326$.

246 Casolari, A.1988. Microbial death. In: M. J. Bazin and J. I. Prosser (Editors), Physiological models in 247 microbiology 2, CRC press, Boca Raton, FL, pp. 1-44.

248 Chiruta, J., Davey, K. R. and Thomas, C. J. Combined effect of temperature and pH on microbial death in 249 continuous pasteurisation of liquids. In: R. Jowitt (Editor), Engineering and Food at ICEF7, Sheffield Academic 250 Press, Sheffield, pp.A109-A112.

251 Cole, M. B., Davies, K. W., Munro, G., Holyoak, C. D. and Kilsby, D. C. 1993. A vitalistic model to describe 252 the thermal inactivation of Listeria monocytogenes. J. Ind. Microbiol. 12: 232-239.

253 Daughtry, B. J., Davey, K. R., Thomas, C. J. and Verbila, A. P. 1997. Food processing: a new model for the 254 thermal destruction of contaminating bacteria. 1997. . In: R. Jowitt (Editor), Engineering and Food at ICEF7, 255 Sheffield Academic Press, Sheffield, pp.A113-A116.

256 Fernandez, A., Salmeron, C., Fernandez, P. S. and Martinez, A. 1999. Application of a frequency distribution 257 model to describe the thermal inactivation of two strains of Bacillus cereus. Trends Food Sci. Technol. 10: 158258162. 
259 Kisby, D. C., Davies, K. W., McClure, P. J., Adair, C. and Anderson, W. A. 2000. Bacterial thermal death 260 kinetics based on probability distributions: the heat destruction of two important food pathogens. $3^{\text {rd }}$ international

261 conference on Predictive Modelling in Foods, September 12-15, 2000. Leuven, Proceedings, pp. 98-100.

262 Linton, R. H., Carter, W. H., Pierson, M. D. and Hackney, C. R. 1995. Use of a modified Gompertz equation to

263 model non linear survival curves for Listeria monocytogenes Scott A. J. Food Protect. 58: 946-954.

264 Peleg, M. 1999. On calculating sterility in thermal and non-thermal preservation methods. Food Res. Int. 32:

$265271-278$

266 Peleg, M. and Cole, M. B. 1998. Reinterpretation of microbial survival curves. Critic. Rev. Food Sci. 38: 353-

267380 .

268 Peleg, M. and Cole, M. B. 2000. Estimating the survival of Clostridium botulinum spores during heat treatments.

269 J. Food Protect. 63: 190-195.

270 Rodrigez, A., Smerage, G., Teixera, A. and Busta, F. 1988. Kinetic effects of lethal temperature on population 271 dynamics of bacterial spores. Trans. Am. Soc. Agric. Eng. 31: 1594-1606.

272 Sapru, V., Teixera, A., Smerage, G. and Lindsay, J. 1992. Predicting thermophilic spore population dynamics for

273 UHT sterilization processes. J. Food Sci. 57: 1248-1252, 1257.

274 Shull, J., Cargo, G. and Ernst, R. 1963. Kinetics of heat activation and thermal death of bacterial spores. Appl.

275 Microbiol. 11: 485.

276 Whiting, R. C. 1993. Modeling bacterial survival in unfavorable environments. J. Ind. Microbiol. 12: $240-246$.

277 Xiong, R., Xie, G., Edmonson, A. E. and Sheard, M. A. 1999. A mathematical model for bacterial inactivation. 278 Int. J. Food Microbiol. 46: 45-55. 
282 Legend figure

283

284 Fig 1:

285 The fit of Equ 3 to the data for the death kinetics of Bacillus pumilus heat injured at $89^{\circ} \mathrm{C}$ 286

$287 \quad$ Fig 2

288 The fit of Equ 3 to the data of Anderson et al. (1996) for the death kinetics of Clostridium 289 botulinum heat injured at $111^{\circ} \mathrm{C}$

290

291

292 Fig 3

293 Registrations of a retort temperature (with an average value of $115.3^{\circ} \mathrm{C}$ ) and inside

294 temperature of a canned tomato sauce

295 


\begin{tabular}{|c|c|}
\hline Temperature $\left({ }^{\circ} \mathrm{C}\right)$ & $\mathrm{p}$ \\
\hline 103 & 0.364 \\
105 & 0.349 \\
107 & 0.432 \\
109 & 0.392 \\
111 & 0.319 \\
113 & 0.314 \\
115 & 0.312 \\
117 & 0.295 \\
119 & 0.337 \\
121 & 0.324 \\
\hline
\end{tabular}


303

Table 2

305

306

\begin{tabular}{|c|c|c|}
\hline Type of spore & Number of data & $\begin{array}{c}\text { Correlation coefficient } \\
\text { between temperature and p- } \\
\text { value }\end{array}$ \\
\hline C. botulinum & 10 & $0.600(0.60)$ \\
B. cereus & 5 & $0.453(0.81)$ \\
B. pumilus & 6 & $0.751(0.75)$ \\
\hline
\end{tabular}

307

308 
Table 3

311

312

\begin{tabular}{|c|c|c|c|}
\hline Type of spore & p-value & z-value & $\mathrm{r}$ \\
\hline C. botulinum & 0.346 & $8.58^{\circ} \mathrm{C}$ & 0.989 \\
B. cereus & 1.37 & $8.57^{\circ} \mathrm{C}$ & 0.997 \\
B. pumilus & 2.24 & $8.04^{\circ} \mathrm{C}$ & 0.998 \\
\hline
\end{tabular}

313

314 
Figure1

317

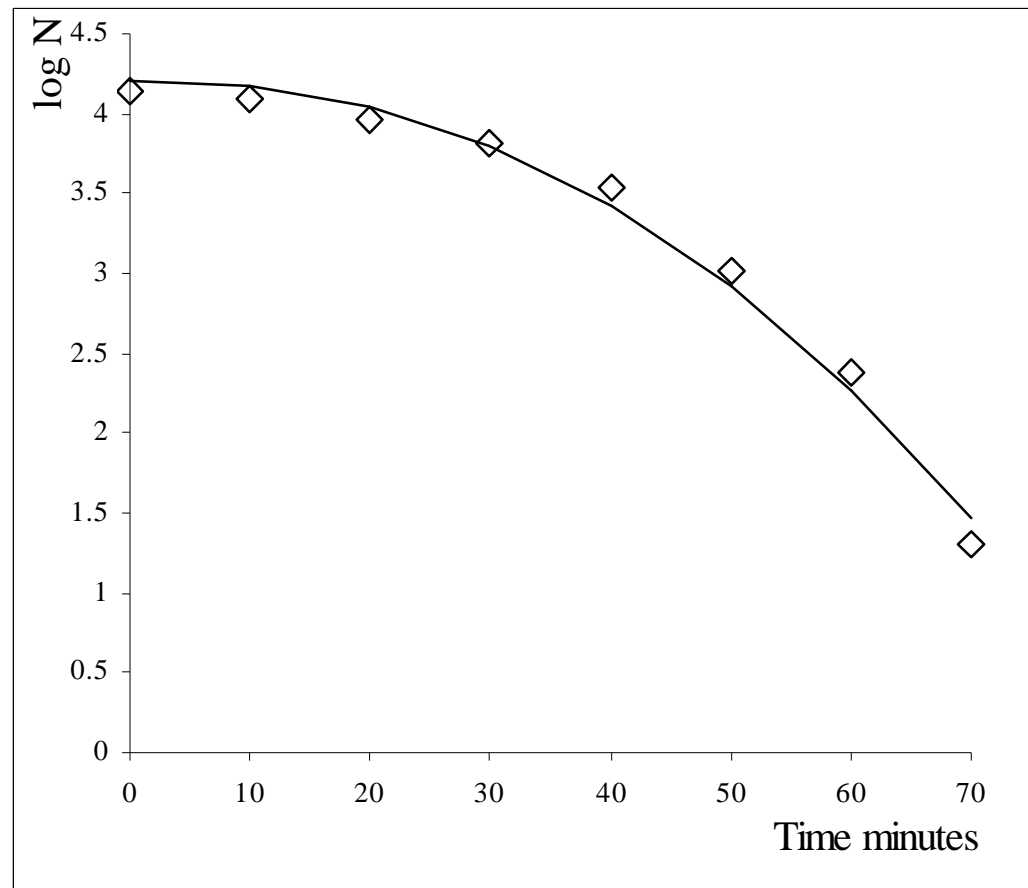


Figure 2

321

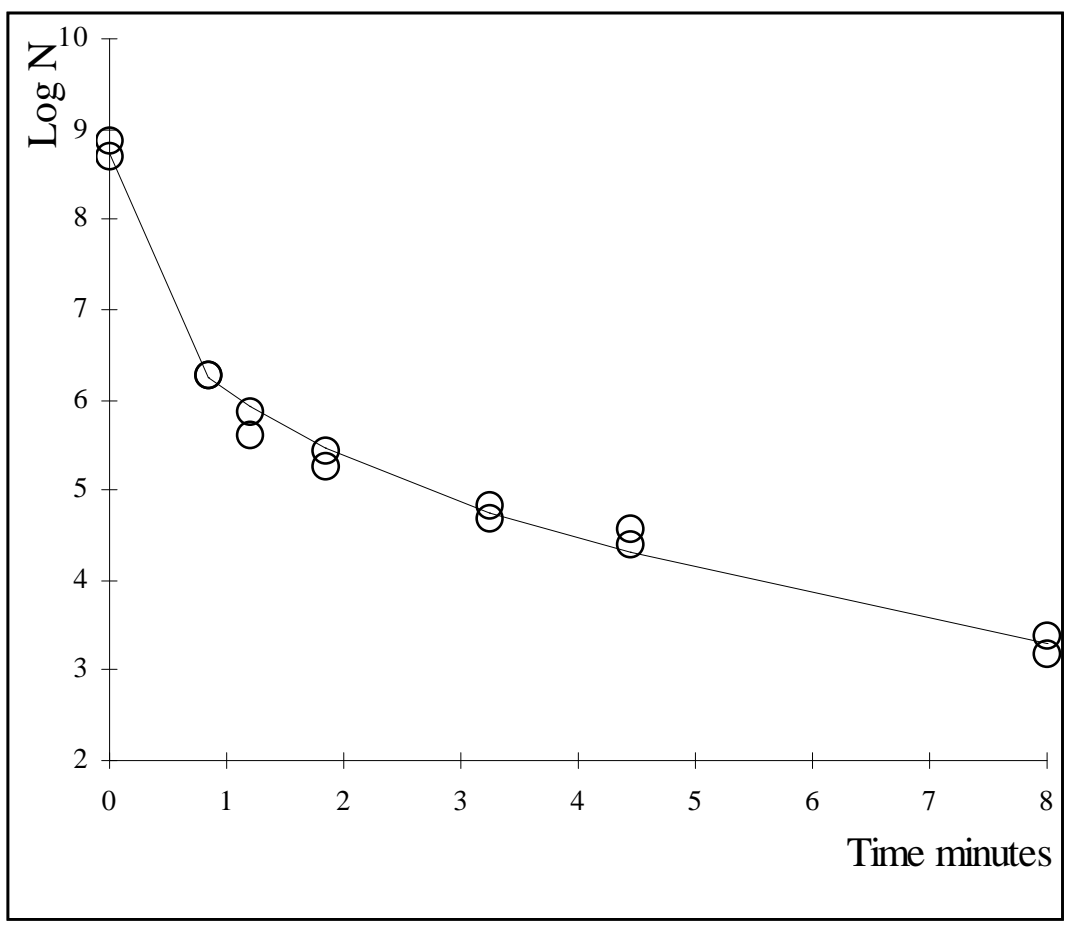

322

323 
Figure 3

326

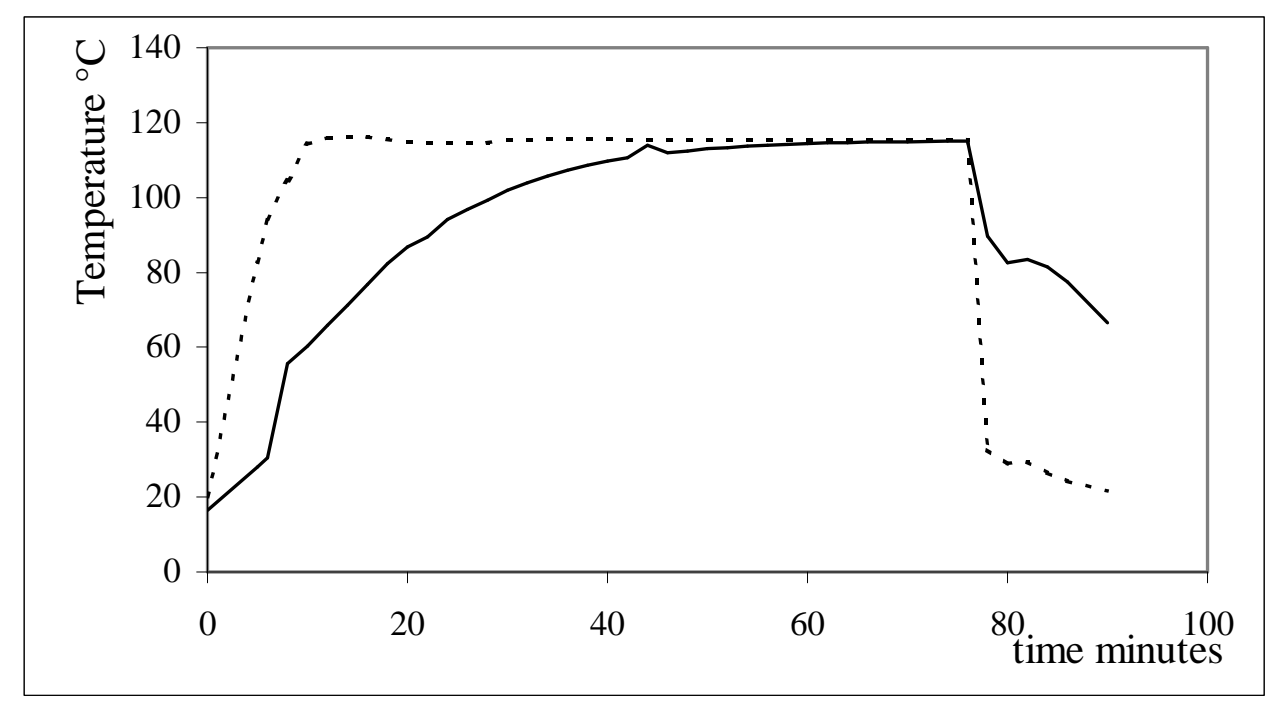

327

328 